\title{
Cost-effectiveness study of oral hypoglycemic agents in the treatment of outpatients with type 2 diabetes attending a public primary care clinic in Mexico City
}

This article was published in the following Dove Press journal:

ClinicoEconomics and Outcomes Research

6 March 2012

Number of times this article has been viewed

\author{
Christian Díaz de León- \\ Castañeda \\ Marina Altagracia-Martínez \\ Jaime Kravzov-Jinich \\ Ma del Rosario Cárdenas- \\ Elizalde \\ Consuelo Moreno-Bonett \\ Juan Manuel Martínez- \\ Núñez \\ Department of Biological Systems \\ and Health Care, Biological and \\ Health Sciences Division, Universidad \\ Autónoma Metropolitana-Xochimilco, \\ Mexico DF, Mexico
}

Correspondence: Marina Altagracia-Martínez Calle la Joya \#I7 Casa 5, Colonia San Juan Tepepan, Mexico DF, Mexico CP 16020 Tel +52 5556764276

Fax +5255 56060535

Email marina.altagraciamartnez3@gmail. com
Introduction: Worldwide, diabetes mellitus presents a high burden for individuals and society. In Latin America, many people with diabetes have limited access to health care, which means that indirect costs may exceed direct health care cost. Diabetes is Mexico's leading cause of death. Purpose: To evaluate the cost-effectiveness ratios of the most used oral hypoglycemic agents (OHA) in the treatment of outpatients with type 2 diabetes attending a public primary care clinic in Mexico City.

Design: A cross-sectional and analytic study was conducted in Mexico City.

Methodology: Twenty-seven adult outpatients with type 2 diabetes who were treated either with metformin or glibenclamide were included. Acarbose was used as an alternative strategy. The study was carried out from the perspective of Mexican society. Direct medical and nonmedical costs as well as indirect costs were evaluated using a structured questionnaire. Efficacies of all drug treatments were evaluated retrospectively. A systematic search was conducted to select published randomized clinical trials based on predetermined inclusion criteria, and treatment success was defined as glycosylated hemoglobin factor $\leq 7 \%$. Efficacy data of each drug and/or combination were analyzed using meta-analysis. The Monte Carlo Markov model was used. Quality-adjusted life-years (QALY) were used as the unit of effectiveness; incremental and sensitive analyses were performed and a 5\% discount rate was calculated. A hypothetical cohort of 10,000 patients was modeled.

Results: The odds ratios of the success of each drug treatment were obtained from the metaanalyses, and were the following: 5.82 (glibenclamide), 3.86 (metformin), 3.5 (acarbose), and 6.76 (metformin-glibenclamide). The cost-effectiveness ratios found were US\$272.63/QALY (glibenclamide), US\$296.48/QALY (metformin), and US\$409.86/QALY (acarbose). Sensitivity analysis did not show changes for the most cost-effective therapy when the effectiveness probabilities or treatment costs were modified.

Conclusion: Glibenclamide is the most cost-effective treatment for the present study outpatient population diagnosed with type 2 diabetes in the early stages.

Keywords: cost-effectiveness, hypoglycemic, outpatients, type 2 diabetes

\section{Introduction}

Worldwide, diabetes mellitus has been recognized as the greatest challenge for all health care systems. ${ }^{1}$ The care of diabetes presents a high burden for individuals and society. People with diabetes are at increased risk of macrovascular and microvascular complications and are more likely than people without diabetes to have other cardiovascular problems. ${ }^{2}$ In Latin America, many people with diabetes have limited 
access to health care, which means that indirect costs may exceed direct health care cost. ${ }^{3}$ Diabetes is also impoverishing families at the household level. According to the International Diabetes Federation (IDF), families in Latin America pay $40 \%-60 \%$ of the cost of diabetes care from their own pockets. ${ }^{4}$

Diabetes is Mexico's leading cause of death. It is one of the most common chronic diseases, with a high prevalence and a growing epidemiologic trend. The IDF estimates that type 2 diabetes in Mexico had a prevalence of $10.8 \%$ in 2010 and a projection of $13.3 \%$ for $2030 . .^{5}$ In Mexico, type 2 diabetes is one of the main causes of premature disability, blindness, end-stage renal insufficiency, and nontraumatic amputation. Diabetes mellitus and ischemic cardiopathy have been the two main causes of mortality since 2000 . $^{6-8}$

In 2010, the total cost of diabetes in Mexico was estimated to be US\$778.5 million, including US\$343.2 million in direct costs and US\$435.2 million in indirect costs. Medical consultations, laboratory tests, drug costs, hospitalizations, and long-term diabetes-related complications are the most common direct costs implicated in diabetes treatment. Permanent and temporary disabilities make up the most common indirect costs. ${ }^{9}$

The public health sector in Mexico is composed of several institutions: the Mexican Institute of Social Security (IMSS in Spanish), the Institute of Social Security in the Service to the State Workers, the Ministry of Health, health institutes, and others. Fifty-eight percent of the Mexican population is affiliated to the IMSS (the largest public health institution). ${ }^{10}$ It provides most of the hospitals, clinics, and health centers to Mexican consumers. Nevertheless, there are an increasing number of Mexicans who are uninsured.

The public health sector has an essential drug list called the "Cuadro Básico y Catálogo de Medicamentos" and its use is compulsory for the entire sector. At present, six oral hypoglycemic agents (OHAs) are included in the Cuadro Básico y Catálogo de Medicamentos: metformin, glibenclamide, acarbose, rosiglitazone, pioglitazone, and sitagliptin. ${ }^{11,12}$ Metformin, glibenclamide, and acarbose are most frequently used in primary care clinics for the pharmacological treatment of type 2 diabetes. The efficacies of these OHAs and the direct acquisition costs of each varies. The Mexican health care systems dedicate substantial resources to the acquisition of OHAs to treat diabetes and associated risk factors but there are few indicators of their effectiveness. ${ }^{1}$ All drugs are provided free of charge to all insured patients.

As diabetes prevalence and incidence rates in Mexico are increasing rapidly, along with the high economic burden of its complications, it is very important to conduct a complete economic evaluation on diabetes treatments to optimize economic resources and contribute to a better quality of life for patients with diabetes. ${ }^{7}$ However, very few economic evaluations have been conducted in Mexico, particularly on type 2 diabetes. ${ }^{9}$ Studies about total costs are important, but complete economic evaluations are needed to make evidencebased health decisions and, consequently, the best risk and cost-effective treatment choices.

The available information suggests ineffective performance of the health care systems. ${ }^{1}$ Outpatients are facing difficulties in properly controlling their blood glucose levels due to lack of economic resources, for example, to acquire blood sugar meters as the public health care systems provide the drugs but not the devices.

Our study was designed to estimate the resource use and expenditure for diabetes in Mexican outpatients. A costeffectiveness (CE) analysis was carried out from the perspective of Mexican society in order to determine the monetary costs per unit of effectiveness of each selected OHA.

\section{Methods}

This research was carried out in an IMSS primary care clinic in Mexico City. The population sample included outpatients $>18$ years of age with type 2 diabetes diagnosed within the 2 years prior to initiation of the present study. Due to the early stage of the disease, we assumed that patients did not have any diabetes complications. The study was carried out from the perspective of Mexican society (public health sector). A 1-year time horizon was considered.

\section{Model structure}

A Markov model ${ }^{13}$ was designed and built to simulate the economic and health outcomes of treatment with OHAs (metformin and glibenclamide; acarbose was used as an alternative strategy) in a hypothetical cohort of 10,000 patients whose type 2 diabetes was diagnosed within the 2 years before the initiation of the present study. Different national and international therapeutic guidelines for the treatment of type 2 diabetes were revised and used in order to build the Markov model. ${ }^{14-18}$

Figure 1 shows the designed Markov model. Two health states were established defined by the glycosylated hemoglobin $\left(\mathrm{HbA}_{1 \mathrm{c}}\right)$ factor: (1) patients with no glycemic control $\left(\mathrm{HbA}_{1 \mathrm{c}}>7.0 \%\right)$ and (2) patients with glycemic control $\left(\mathrm{HbA}_{1 \mathrm{c}} \leq 7.0 \%\right)$. A unidirectional transition from the first health state to the second, the probability of which corresponds to treatment success, was considered. The 


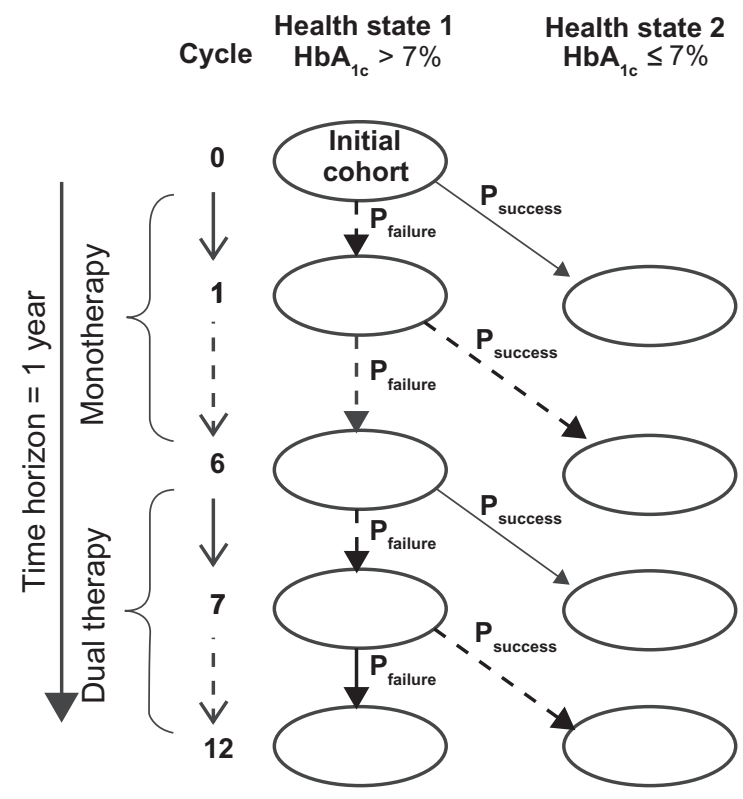

Figure I Cascade diagram. Markov model design. Abbreviation: $\mathrm{HbA}_{1 \mathrm{c}}$, glycosylated hemoglobin factor.

1-year time horizon was divided into 12 cycles of 1 month each: six cycles of first-line therapy and six cycles of rescue therapy with dual therapy used in cases of metformin or glibenclamide monotherapy (glibenclamide addition to the metformin or vice versa) failure; in the case of acarbose failure, addition of another pharmacological agent was not considered. In each health state, we assessed the presence or absence of primary nonserious adverse events (NSAEs) associated with treatment using the evaluated OHAs.

\section{Transition probabilities}

A systematic search of clinical trials in the medical literature was conducted for 1980-2009. The electronic databases consulted included PubMed, ${ }^{19}$ Scopus,${ }^{20}$ Cochrane Library, ${ }^{21}$ and Medline. ${ }^{22}$ The search words (individually or in combination) were as follows: diabetes, diabetes mellitus, noninsulin-dependent diabetes mellitus, metformin, glibenclamide, acarbose, and clinical trial. Inclusion criteria for the clinical tests' selection were the following: doubleblind, randomized, and placebo-controlled trials (except in the cases of dual therapy); adult patients with type 2 diabetes (without gender distinction), with an average $\mathrm{HbA}_{1 \mathrm{c}} \leq 9 \%$, and with an average body mass index $\leq 30 \mathrm{~kg} / \mathrm{m}^{2}$; and final $\mathrm{HbA}_{\mathrm{lc}}$ levels reported in the study.

A value of $\mathrm{HbA}_{1 \mathrm{c}} \leq 7.0 \%$ was considered treatment success. Efficacy data of the $\mathrm{HbA}_{1 \mathrm{c}}$ level reduction gathered from the medical literature were analyzed by metaanalysis. Revman Manager 5.0.24 software (The Cochrane
Collaboration, Copenhagen, Denmark) was used to perform the meta-analysis and to obtain odds ratios (ORs) within a $95 \%$ confidence interval $(95 \% \mathrm{CI})$ for each treatment strategy. An aleatory effects model was considered. The success probability of each therapeutic alternative was calculated from the OR data.

The occurrence probabilities of NSAEs associated to the OHA treatments were gathered from the selected clinical trial and published studies by The Cochrane Library.

\section{Costs}

Direct medical costs included medical care costs, laboratory tests, and the acquisition drug costs in 2009, which were investigated through the national Federal Official Daily Gazette publication and the IMSS 2009 bidding drug results published at its website (drug costs). ${ }^{23,24}$ In the Mexican public health system, drugs and health services are given free of charge to all insured members of the population.

Four medical visits, four laboratory tests per patient, and administration of the maximum tolerated doses of each drug were assumed. Nonmedical direct costs (transportation) and indirect costs (lost working time or days) were evaluated through a structured questionnaire given to 27 patients with type 2 diabetes who were affiliated with the IMSS primary care clinic and who were receiving metformin, glibenclamide, or the metformin-glibenclamide combination. Acarbose treatment was included based on the national guidelines, but none of the 27 patients were treated with acarbose. The metformin $(850 \mathrm{mg} /$ tablet $)$, glibenclamide (5 $\mathrm{mg} /$ tablet), and acarbose (50 $\mathrm{mg} / \mathrm{tablet})$ monotherapies maximum daily defined doses were $2550 \mathrm{mg}$ (three tablets), $20 \mathrm{mg}$ (four tablets), and $300 \mathrm{mg}$ (six tablets) respectively. The metformin-glibenclamide combination maximum daily defined dose was $1700 \mathrm{mg}$ (two tablets) of metformin and $15 \mathrm{mg}$ ( 3 tablets) of glibenclamide. The drug costs per each tablet are the following: $:{ }^{24}$ metformin $\$ 0.0098$, glibenclamide $\$ 0.0032$, and acarbose $\$ 0.0317$. All costs were calculated in US dollars. The US dollar exchange rate to Mexican pesos was US\$1 = MXN\$13.35 (January 2009).

All patients gave informed consent before answering the cost questionnaire and their confidentiality was respected.

To calculate the costs associated with lost working time, the minimum wage prevailing in Mexico City in 2010 was assumed ( $\$ 4.1$ per day). ${ }^{25}$

\section{Cost-effectiveness analysis}

The TreeAge ${ }^{\circledR}$ Pro Suite 2009 (TreeAge Software Inc, Williamstown, MA) software was used to program the 
Monte Carlo Markov model designed as a decision tree. The treatment success probabilities obtained from the meta-analysis of each OHA were used. Monthly costs of therapeutic alternatives were employed in the model. The health outcomes obtained were quantified in terms of qualityadjusted life-years (QALY). A hypothetical cohort of 10,000 patients was considered in order to obtain the $\mathrm{CE}$ ratio of each therapeutic alternative as well as the final proportions of patients with treatment success or failure and the presence of NSAEs. Univariate sensitivity analysis was carried out to evaluate the effect of the parameter uncertainty evaluated on the $\mathrm{CE}$ ratios obtained. The annual total costs varied by $\pm 25 \%$, and the confidence interval of the OR obtained from the metaanalysis was used for this purpose. An incremental CE ratio (ICER) analysis of the dominant treatments in relation to the most cost-effective treatment was performed. Updated annual costs of each treatment were determined assuming a $5 \%$ discount rate and 5 years into the future.

\section{Results}

\section{Transition probabilities}

To determine the efficacy of each drug evaluated in this study, clinical trials were selected according to inclusion criteria. As a result of the scientific literature systematic review, four clinical trials were selected that included a total of 766 patients for the metformin group and 496 patients in the placebo group. ${ }^{26-29}$ Two clinical trials meeting the inclusion criteria for glibenclamide included a total of 188 patients in the treatment group and 186 in the treatment group. ${ }^{28-30}$ For treatment with acarbose, two clinical trials were selected that included a total of 90 patients in the treatment group and 88 patients in the placebo group. ${ }^{30,32}$

When glibenclamide or metformin treatment failed, the recommendations of the therapeutic guidelines were used in order to choose the second-line treatment. Therapeutic guidelines recommend the addition of glibenclamide after therapeutic failure of metformin and vice versa. In the case of metformin failure, the only clinical trial meeting the inclusion criteria included 103 patients in whom glibenclamide was added to the initial monotherapy (metformin + glibenclamide) and 104 patients who continued metformin monotherapy (control group). ${ }^{32}$ The 2 clinical trials selected for glibenclamide failure included 350 patients in whom metformin was added to the initial monotherapy (glibenclamide + metformin) and 341 patients who continued glibenclamide monotherapy (control group). ${ }^{26,33}$

The final $\mathrm{HbA}_{1 \mathrm{c}}$ outcomes of each treatment reported in the selected clinical trial were analyzed by meta-analysis except for the metformin + glibenclamide combination since only one study was considered. Table 1 shows the meta-analysis outcomes. The ORs with $95 \%$ confidence intervals are as follows: 3.86 (2.72-5.47) for metformin (Table 1A), 5.82 (3.54-9.56) for glibenclamide (Table 1B), 3.50 (1.52-8.03) for acarbose (Table 1C), and 6.76 (4.38-10.46) for glibenclamide + metformin combination therapy (Table 1D). Table 1 does not show the outcome of the metformin + glibenclamide combined therapy, but a 2.88 (1.63-5.09) OR was obtained. The OR values were transformed to treatment success probabilities and $0.2315,0.2582$, and 0.2217 were obtained for monotherapy with metformin, glibenclamide, and acarbose, respectively. The probabilities of the dual therapies were 0.2022 for glibenclamide + metformin and 0.2893 for metformin + glibenclamide.

Regarding the NSAEs, the following frequencies were seen: metformin-associated gastrointestinal problems, 53.9\%; glibenclamide-related gastrointestinal and hypoglycemia problems, 27.6\%; acarbose-related gastrointestinal problems, $77.6 \%$; and metformin + glibenclamide combination-related gastrointestinal plus hypoglycemia problems, 52.4\%. ${ }^{32-35}$

\section{Costs}

Direct medical costs were US\$154.90 for medical visits and US\$21.57 for laboratory tests for the three OHA and the metformin + glibenclamide combination. The annual drug costs were calculated as follows: metformin, US\$10.74; glibenclamide, US\$4.61; acarbose, \$69.44; and metformin + glibenclamide combination, US\$10.62. With regard to transportation cost (nonmedical direct cost), an average cost of US\$5.03 for metformin, US\$6.44 for glibenclamide, and US\$22.92 for the metformin + glibenclamide combination was calculated. With regard to indirect costs, none of the persons interviewed declared losing a complete working day, only working hours. The lost income cost was as follows: US\$0.47 for metformin, US\$0.58 for glibenclamide, and US $\$ 0.06$ for the metformin + glibenclamide combination. In general, the lost working time cost was low because patients had a diagnosis of type 2 diabetes $<2$ years prior and had not yet experienced severe disease-related complications.

The total annual costs per OHA per patient were as follows: metformin, US\$192.71; glibenclamide, US\$188.10; acarbose, US\$245.91; and metformin + glibenclamide combination, US\$210.07.

\section{Cost-effectiveness analysis}

Figure 2 shows the design of the Monte Carlo Markov cycles decision tree. The tree was programmed with the transition 


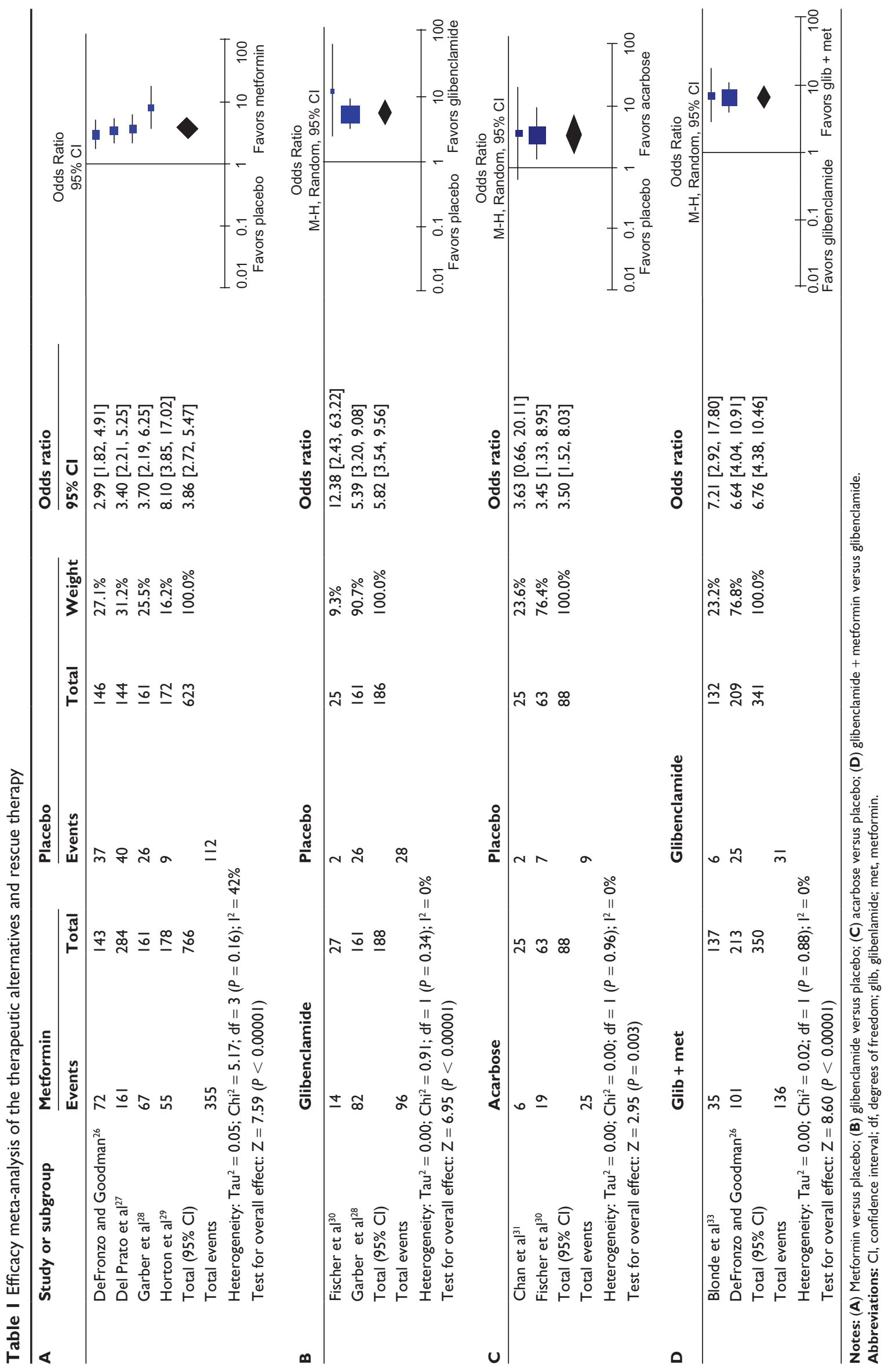




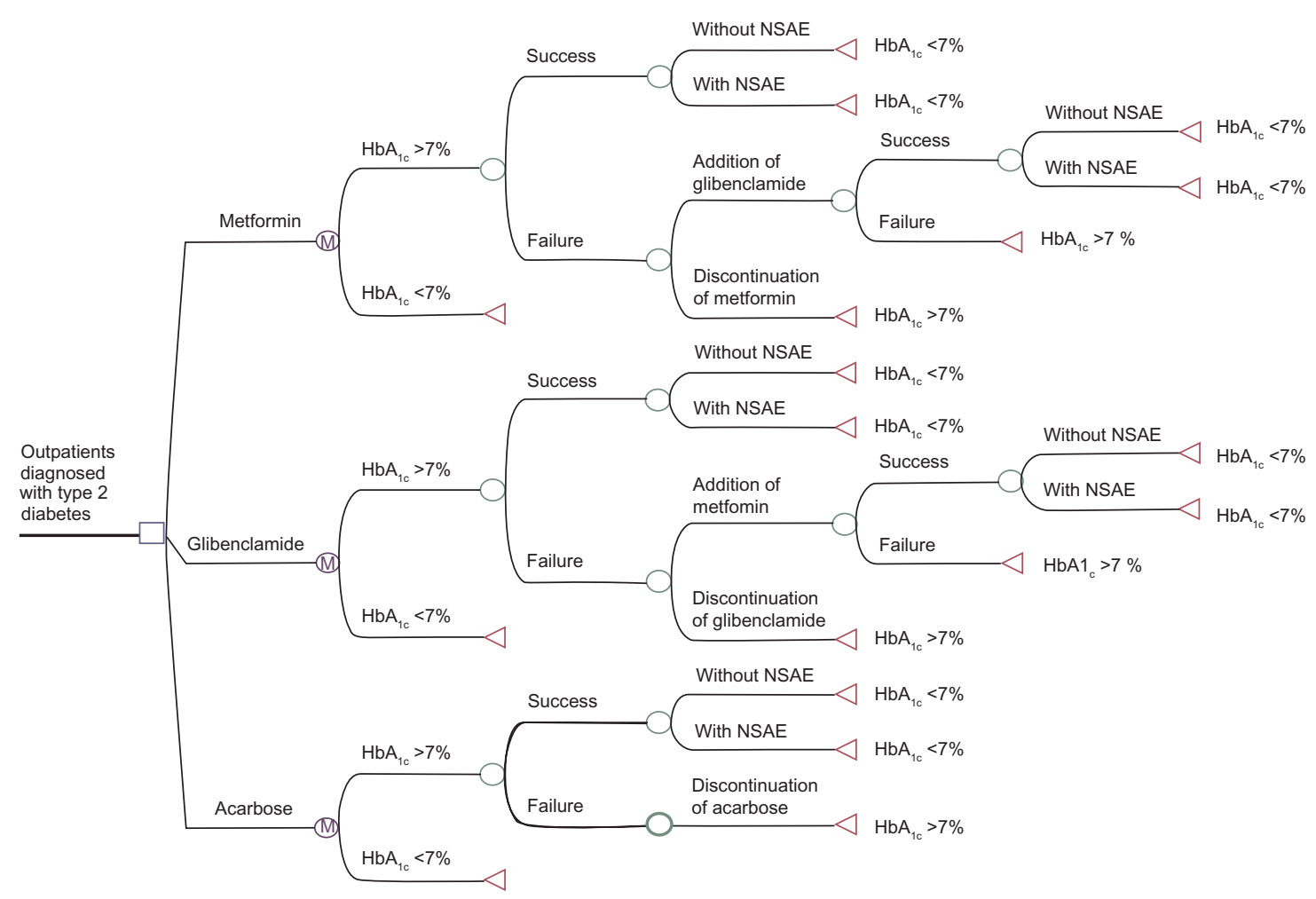

Figure 2 Markov model as a decision tree designed using the TreeAge ${ }^{\circledR}$ program.

Notes: $\square=$ the node of the decision to be made; $\mathbb{M}=$ represents Markov nodes; $\bigcirc=$ random nodes (in the probabilities function); $\triangleleft=$ branch end finished in a health state. The hypothetical patient cohort begins with the health state characterized by $\mathrm{HbA}_{\mathrm{lc}}>7 \%$.

Abbreviations: $\mathrm{HbA}_{1 \mathrm{c}}$, glycosylated hemoglobin factor; NSAE, nonserious adverse event.

probabilities obtained from the meta-analysis as well as with the monthly estimated costs of each therapeutic alternative. The CE ratios were as follows: metformin, US\$296.48/ QALY; glibenclamide, US\$272.63/QALY; and acarbose, US\$409.86/QALY. The NSAE frequencies were as follows: metformin, $53.6 \%$ (gastrointestinal); glibenclamide, 31.3\% (gastrointestinal/hypoglycemia); and acarbose, $77.6 \%$ (gastrointestinal).

\section{Sensitivity analysis}

Figure $3 \mathrm{~A}-\mathrm{C}$ shows the univariate sensitivity analyses of the evaluated treatment alternatives. It can be observed that glibenclamide is the dominant therapy over metformin and acarbose. When the monthly treatment costs varied (Figure 3A), the glibenclamide CE ratio remained the most cost-effective therapy. When the monotherapy success probability varied (Figure $3 \mathrm{~B}$ ), the glibenclamide CE ratio remained the most cost-effective therapy. When the metformin + glibenclamide combination therapy success probability (Figure 3C) varied, no $\mathrm{CE}$ ratio variation was observed. In short, glibenclamide + metformin dual therapy was more cost-effective than metformin + glibenclamide treatment.

\section{Incremental analysis and discount rate}

The outcome of the ICER for glibenclamide versus metformin was US\$114.83/QALY, while that for glibenclamide versus acarbose was US $\$ 642.19 / \mathrm{QALY}$. The update to 5 years' use of glibenclamide, the most cost-effective treatment, was US\$146.85.

\section{Discussion}

Glibenclamide was the most cost-effective treatment for patients whose type 2 diabetes had been diagnosed in the early stages.

Direct medical costs for type 2 diabetes patients are high, representing a high economic burden for health institutions like IMSS that provide these services and drugs. ${ }^{1}$ Out-ofpocket type 2 diabetes treatments for patients represent a high economic burden for the uninsured population as well as for the insured one. ${ }^{2}$ The situation is more serious when it comes to patients who earn the minimum wage, as the average annual treatment cost is US\$196.60 and represents $14.3 \%$ of the patient's annual income (US\$1,377.60). ${ }^{25}$

With regard to the efficacy of the evaluated therapeutic alternatives to control hyperglycemia levels, the metaanalysis showed that glibenclamide treatment is more 


\section{A}

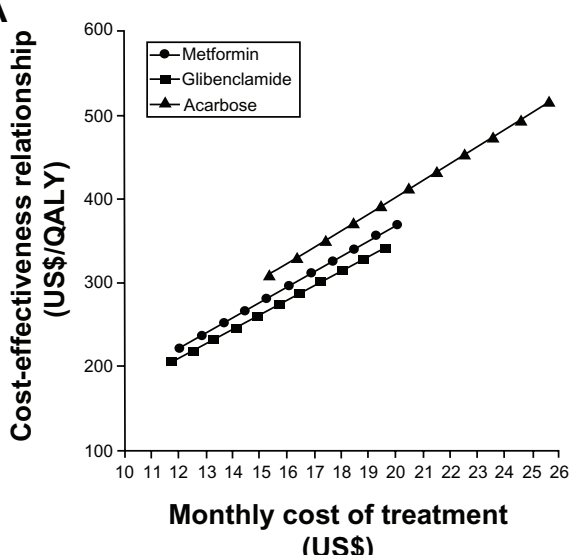

(US\$)
B

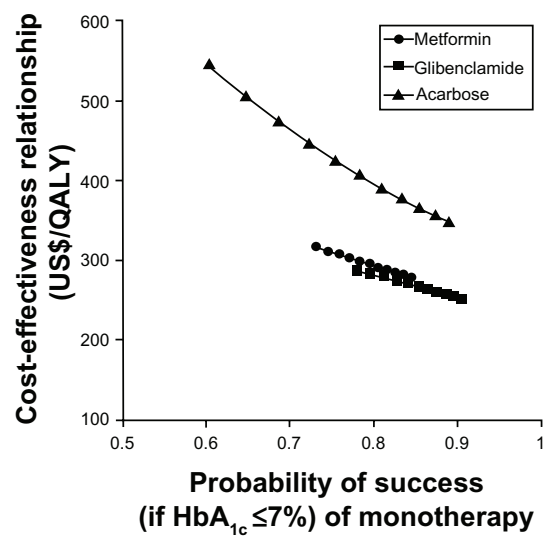

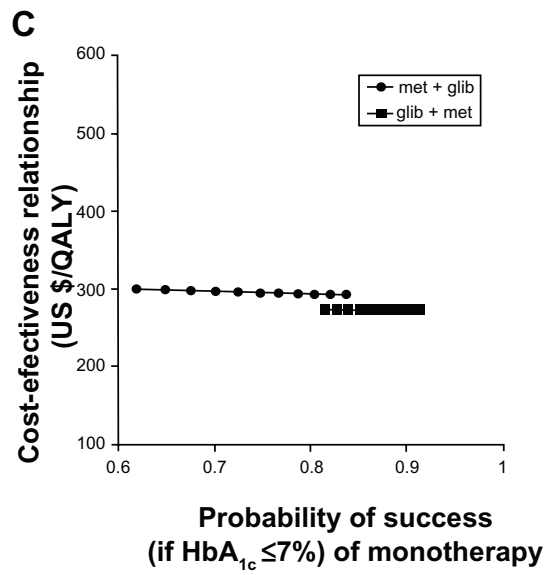

Figure 3 Sensitivity analysis. (A) Cost-effectiveness (CE) relationship in terms of uncertainty of the monthly total costs per patient. (B) CE relationship in terms of the uncertainty of the metformin, glibenclamide, or acarbose monotherapy success probability ("success" being $\mathrm{HbA}_{\mathrm{Ic}} \leq 7 \%$ ). (C) $\mathrm{CE}$ relationship in terms of the uncertainty of the metformin with glibenclamide dual therapy success probability ("success" if $\mathrm{HbA}_{\mathrm{lc}} \leq 7 \%$ ).

Notes: met + glib refers to glibenclamide addition after metformin monotherapy failure; glib + met refers to metformin addition after glibenclamide monotherapy failure.

effective than metformin or acarbose treatment. With regard to the efficacy analysis of the metformin + glibenclamide combination, metformin addition after glibenclamide monotherapy failure showed higher efficacy than glibenclamide addition after metformin monotherapy failure.

The present study might give policy decision makers important information about how to allocate the necessary resources for diabetes and to meet the increasing demand for diabetes treatments. Long-term costs can be reduced when the right treatment is chosen in the early stages of the disease.

Glibenclamide monotherapy was found to be the most cost-effective in the simulation model of a 10,000-patient hypothetical cohort. This may be the reason why it is the most commonly recommended option in the initial oral pharmacological treatment of patients with type 2 diabetes. However, according to the health outcomes observed metformin has a very close $\mathrm{CE}$ ratio and could be considered as the second choice. As acarbose resulted in the highest costs per unit of effectiveness, it is the least recommended treatment and could be used in the treatment of patients in whom glibenclamide or metformin treatment is contraindicated due to renal failure or other causes and/or in patients of advanced age. ${ }^{36,37}$

The ICER results showed that each QALY gained with metformin treatment is US\$114.83 more expensive than that with glibenclamide treatment, whereas each QALY gained with acarbose treatment is US\$642.19 more expensive than that with glibenclamide treatment. Metformin and acarbose treatments were the therapeutic options dominated by glibenclamide.

In the present study, the total direct nonmedical and indirect costs were lower than the total direct medical costs. In an earlier study on costs of type 2 diabetes conducted in the IMSS, the total direct and indirect nonmedical costs were higher than the total medical direct costs. ${ }^{10}$ However, the patients included in the present study were in the early stages of the disease and long-term diabetes-related complications were not yet present. In addition, patients were treated at a public primary care clinic and medical care 
costs were lower than those of a highly specialized hospital. Moreover, diabetes is a degenerative chronic disease that requires treatment throughout a patient's life span and causes prolonged work disability; such features might increase the direct nonmedical and indirect costs. These aspects might explain the differences in costs and in the CE analysis.

The results of our study are supported by the robustness of the model evaluated through univariate sensitivity analysis but we acknowledge a small population sample was used to calculate the treatment costs. In building this model, great effort was put into collecting updated, representative, and consistent information; therefore, the conclusions that can be drawn from it are valid and the probability of bias is small. The hypothetical cohort of 10,000 patients modeled was intended to soften the impact of the bias. Analytical models are generally used for that purpose.

\section{Conclusion}

Glibenclamide is the most cost-effective treatment for the present study outpatient population diagnosed with type 2 diabetes in the early stages. Further similar investigations including a larger population sample are needed in order to draw definitive conclusions.

\section{Disclosure}

The authors declare no conflicts of interest in this work.

\section{References}

1. González-Villalpando C, López-Ridaura R, Campuzano JC. GonzálezVillalpando ME. The status of diabetes care in Mexican population: Are we making a difference? Results of the National Health and Nutrition Survey 2006. Salud Publica Mex. 2010;52 Suppl 1:36-46.

2. Simpson SH, Corabian P, Jacobs P, Johnson JA. The cost of major comorbidity in people with diabetes mellitus. CMAJ. 2003; 168(13):1661-1667.

3. Barceló A, Aedo C, Rjpathak S, Robles S. The cost of diabetes in Latin America and the Caribbean. Bull World Health Organ. 2003;81(1):19-27.

4. International Diabetes Federation. Available from http://www.idf.org/. Accessed May 12, 2011.

5. International Diabetes Federation (IDF). Prevalence estimates of diabetes mellitus. 2010. Available from: http://www.diabetesatlas.org/downloads. Accessed February 24, 2011.

6. Rull JA, Aguilar-Salinas CA, Rojas R, Ríos-Torres JM, Gómez-Perez FJ, Olaiz G. Epidemiology of type 2 diabetes in Mexico. Arch Med Res. 2005;36(3):188-196.

7. Córdova-Villalobos JA, Barriguete-Meléndez JA, Lara-Esqueda A, et al. Chronic non-communicable diseases in Mexico: epidemiologic synopsis and integral prevention. Salud Publica Mex. 2008;50(5):419-427.

8. Instituto Nacional de Estadística, Geografía e Historia (INEGI). Principales causas de defunción en México en el año 2008. [Principal reasons of death in Mexico in 2008.] 2010. Available from: http://www.inegi.org. $\mathrm{mx} /$ Sistemas/temasV2/Default.aspx?s=est\&c=17484. Accessed April 30, 2010.

9. Arredondo A, de Icaza E. Financial requirements for the treatment of diabetes in Latin America: implications for the health system and for patients in Mexico. Diabetologia. 2009;52(8):1693-1695.
10. Arredondo A, Zúñiga A. Economic consequences of epidemiological changes in diabetes in middle-income countries: the Mexican case. Diabetes Care. 2004;27(1):104-109.

11. Consejo de Salubridad General. Edición 2008 del Cuadro Básico y Catálogo de Medicamentos (CByCM). Diario Oficial de la Federación (DOF). 25 de marzo del 2009. Tercera y Cuarta sección. [2008 edition of the Drug Essential List (CByCM). Federal Official Daily Gazette (DOF). March 25, 2009. Third and Fourth section.] Spanish.

12. Consejo de Salubridad General. Primera actualización de la Edición 2008 del Cuadro Básico y Catálogo de Medicamentos. Diario Oficial de la Federación (DOF). 08 de abril del 2009. Tercera sección. [First update of 2008 edition of the Essential Drug List (CByCM). Federal Official Daily Gazette (DOF). April 8, 2009. Third section.] Available from: http://www.ordenjuridico.gob.mx/Federal/PE/APF/APC/SSA/ Aclaraciones/2009/08042009\%281\%29.pdf. Accessed December 6, 2011. Spanish.

13. Muening P. Designing and Conducting Cost-Effectiveness Analyses in Medicine and Health Care. San Francisco, CA: Jossey-Bass; 2002.

14. Secretaría de Salud. Modificación a la Norma Oficial Mexicana NOM-015SSA2-1994, Para la prevención, tratamiento y control de la diabetes mellitus en la atención primaria para quedar como Norma Oficial Mexicana NOM-015-SSA2-1994, Para la prevención, tratamiento y control de la diabetes. Diario Oficial de la Federación (DOF). 18 de enero del 2001. Primera sección. [Modification to the Official Mexican Norm NOM-015-SSA2-1994, For the prevention, treatment and control of the diabetes mellitus in the primary care to stay as Official Mexican Norm NOM-015-SSA2-1994, For the prevention, treatment and control of the diabetes. Official diary of the Federation (DOF). January 18, 2001. First section.] Available from: http://www.sideso.df.gob.mx/ documentos/legislacion/NOM_015_SSA2.pdf. Accessed December 6, 2011. Spanish.

15. Gil LE, Domínguez ER, Sil MJ, Parrilla JI, de Santillana SP, Torres LP. Diagnóstico y tratamiento de la diabetes mellitus tipo 2 en el primer nivel de atención. México, Instituto Mexicano del Seguro Social. [Diagnosis and treatment of the diabetes mellitus type 2 in the primary attention level. Mexico, Mexican Social Security Institute], 2009. Spanish.

16. González CA, Valdez LA, Cruz EA, et al. Diagnóstico, metas de control ambulatorio y referencia oportuna de la diabetes mellitus tipo 2 en el primer nivel de atención. México, CENETEC-Secretaría de Salud. [Diagnosis, goals of outpatients control and opportune reference of the type 2 diabetes in the primary attention level. Mexico, CENETECMinistry of Health], 2008. Spanish.

17. National Collaborating Centre for Chronic Conditions. Type 2 diabetes: national clinical guideline for management in primary and secondary care. London, Royal College of Physicians, 2008. Available from: http:// www.nice.org.uk/nicemedia/pdf/CG66 NICEGuideline.pdf. Accessed December 6, 2011.

18. Grupo de trabajo de la Guía de Práctica Clínica sobre Diabetes tipo 2. Guía de Práctica Clínica sobre Diabetes tipo 2. Madrid, Agencia de Evaluación de Tecnologías Sanitarias del País Vasco, 2008. [Workgroup of the Clinical Practice Guide on type 2 diabetes. Clinical Practice Guide on type 2 diabetes. Madrid, Evaluation of Health Technologies Agency of the Basque Country, 2008.] Available from: http://www. guiasalud.es/GPC/GPC_429_Diabetes_2_Osteba_compl.pdf. Accessed December 6, 2011. Spanish.

19. PubMed.gov [database on the Internet]. Bethesda, MD: National Center for Biotechnology Information, US Library of Medicine; nd. Available from: http://www.ncbi.nlm.nih.gov/pubmed/. Accessed December 6, 2011.

20. SciVerse Scopus [database on the Internet]. Amsterdam: Elsevier; 2011. Available from: http://www.scopus.com/home.url. Accessed December 6, 2011.

21. The Cochrane Library [database on the Internet]. Hoboken, NJ: John Wiley and Sons; 2010. Available from: http://www.thecochranelibrary. com/view/0/index.html. Accessed December 6, 2011.

22. MEDLINE ${ }^{\circledR}$ [database on the Internet]. Bethesda, MD: National Library of Medicine; nd. Available from: http://www.ncbi.nlm.nih.gov/pubmed/. Accessed December 6, 2011. 
23. Instituto Mexicano del Seguro Social (IMSS). Costos Unitarios por Nivel de Atención Médica para el año 2009. Diario Oficial de la Federación (DOF). 6 de marzo del 2009. [Unitary costs for Medical Attention Level. Federal Official Daily Gazette (DOF). March 6, 2009.] Available from: http://www.consultoriofiscalunam.com.mx/seccion-6-6. html. Spanish.

24. Instituto Mexicano del Seguro Social. Portal de Transparencia [Website of Transparent Information]. Available from: http://transparencia.imss. gob.mx/. Accessed June 23, 2009. Spanish.

25. Servicio de Administración Tributaria (SAT). Salarios Mínimos durante el 2009 [Minimum wages in 2009]. Available from: http://www.sat.gob. $\mathrm{mx} /$ sitio_internet/asistencia_contribuyente/informacion_frecuente/ salarios_minimos/45_13706.html. Accessed March 23, 2011. Spanish.

26. DeFronzo RA, Goodman AM. Efficacy of metformin in patients with non-insulin-dependent diabetes mellitus. The Multicenter Metformin Study Group. N Engl J Med. 1995;333(9):541-549.

27. Del Prato S, Erkelens DW, Leutenegger M. Six-month efficacy of benfluorex vs placebo or metformin in diet-failed type 2 diabetic patients. Acta Diabetol. 2003;40(1):20-27.

28. Garber AJ, Larsen J, Schneider SH, Piper BA, Henry D. Simultaneous glibenclamide/metformin therapy is superior to component monotherapy as an initial pharmacological treatment for type 2 diabetes. Diabetes Obes Metab. 2002;4(3):201-208.

29. Horton ES, Clinkingbeard C, Gatlin M, Foley J, Mallows S, Shen S. Nateglinide alone and in combination with metformin improves glycemic control by reducing mealtime glucose levels in type 2 diabetes. Diabetes Care. 2000;23(11):1660-1665.
30. Fischer S, Patzak A, Rietzsch H, et al. Influence of treatment with acarbose or glibenclamide on insulin sensitivity in type 2 diabetic patients. Diabetes Obes Metab. 2003;5(1):38-44.

31. Chan JC, Chan KW, Ho LL, et al. An Asian multicenter clinical trial to assess the efficacy and tolerability of acarbose compared with placebo in type 2 diabetic patients previously treated with diet. Asian Acarbose Study Group. Diabetes Care. 1998;21(7):1058-1061.

32. Marre M, Howlett H, Lehert P, Allavoine T. Improved glycaemic control with metforming libenclamide combined tablet therapy (Glucovance) in type 2 diabetic patients inadequately controlled on metformin. Diabet Med. 2002;19(8):673-680.

33. Blonde L, Rosenstock J, Mooradian AD, Piper BA, Henry D. Glibenclamide/metformin combination product is safe and efficacious in patients with type 2 diabetes failing sulphonylurea therapy. Diabetes Obes Metab. 2002;4(6):368-375.

34. Saenz A, Fernández-Esteban I, Mataix A, Ausejo M, Roque M, Moher D. Metformin monotherapy for type 2 diabetes mellitus. Cochrane Database Syst Rev. 2005;(3):CD002966.

35. Van de Laar FA, Lucassen PL, Akkermans RP, Van de Lisdonk EH, Rutten GE, Van Weel C. Alpha-glucosidase inhibitors for type 2 diabetes mellitus. Cochrane Database Syst Rev. 2005;(2):CD003639.

36. Saenz A, Fernandez-Esteban I, Mataix A, Ausejo Segura M, Roqué i Figuls M, Moher D. Metformin monotherapy for type 2 diabetes mellitus. Cochrane Database Syst Rev. 2005;(3):CD002966.

37. Salpeter SR, Greyber E, Pasternak GA, Salpeter EE. Risk of fatal and nonfatal lactic acidosis with metformin use in type 2 diabetes mellitus. Cochrane Database Syst Rev. 2010;(4):CD002967.
ClinicoEconomics and Outcomes Research

\section{Publish your work in this journal}

ClinicoEconomics \& Outcomes Research is an international, peerreviewed open-access journal focusing on Health Technology Assessment, Pharmacoeconomics and Outcomes Research in the areas of diagnosis, medical devices, and clinical, surgical and pharmacological intervention. The economic impact of health policy and health systems

\section{Dovepress}

organization also constitute important areas of coverage. The manuscript management system is completely online and includes a very quick and fair peer-review system, which is all easy to use. Visit http://www.dovepress.com/testimonials.php to read real quotes from published authors. 